\title{
Torture does not work
}

\author{
Donald Trump's recently declared belief that torture is an effective method of interrogation is misguided \\ and has no basis in evidence.
}

In an $\mathrm{ABC}$ News interview on 26 January 2017, Donald Trump was asked whether he intended to keep his pre-election promise to bring back waterboarding and "a hell of a lot worse". He replied: "I want to do everything within the bounds of what you're allowed to do legally. But do I feel it works? Absolutely, I feel it works."

More than two centuries ago, Napoleon Bonaparte disagreed": "It has always been recognized that this way of interrogating men, by putting them to torture, produces nothing worthwhile. The poor wretches say anything that comes into their mind and what they think the interrogator wishes to know."

The evidence singularly sides with Napoleon, rather than Trump. Everything we know from psychology, physiology, neuroscience, and psychiatry about behaviour and the brain under extreme stress, pain, sleep deprivation, extremes of hot and cold suggests that torture as a method for information extraction does not work - it may produce information, but that information is not reliable ${ }^{2}$. There are also numerous first-hand reports of torture survivors that make the point amply: an individual subjected to torture will say anything to make it stop ${ }^{2}$.

On the other hand, beyond anecdotes, there is no evidence to support coercion as an effective form of interrogation. In fact, there is evidence showing that non-coercive forms of interrogation are much more effective than coercion ${ }^{3,4,5}$. For example, Goodman-Delahunty and colleagues ${ }^{3}$ interviewed 64 law enforcement practitioners and detainees from five different countries, who were involved in high-stakes cases, mainly in alleged acts of terrorism. They found that reported confessions and admissions of guilt were four times more likely when the interrogators adopted a respectful interview strategy that aimed at building rapport with the detainee.

On 16 April 2009, a set of memoranda was released - now widely referred to as the torture memos - that provided legal arguments to justify the CIA (Central
Intelligence Agency)'s use of "enhanced interrogation techniques" on highvalue terror detainees during the Bush administration. The techniques had been devised by two psychologists with no expertise in interrogation, James Mitchell and Bruce Jessen, and have been widely discredited, including by a detailed report of the Senate Select Committee on Intelligence produced in 2012 and declassified in $2014^{6}$.

\section{Everything we know from psychology, physiology, neuroscience, and psychiatry \\ [...] suggests that torture as a method for information extraction does not work.}

Abu Zubaydah was the first detainee to be subjected to the CIA's enhanced interrogation techniques. Over 17 days in August 2002, he was subjected to walling, attention grasps, slapping, facial hold, stress positions, cramped confinement in a coffin, white noise and sleep deprivation for almost 24 hours a day. He was waterboarded 2-4 times a day, which led to spasms, vomiting and, occasionally, loss of consciousness. He was described as "distressed to the level that he was unable to effectively communicate".

The CIA's enhanced interrogation of Abu Zubaydah yielded absolutely no intelligence. On the other hand, under non-coercive interrogation, Abu Zubaydah had previously provided copious useful intelligence, including the identification of Khalid Sheikh Mohammed as the mastermind of the $9 / 11$ attacks $^{6}$.

The CIA's use of enhanced interrogation techniques during the Bush administration caused international controversy when it became public. The revelation was soon followed by another disturbing set of facts: senior officials at the American Psychological Association colluded with the US Department of Defense for the greater part of a decade following the 2001 terrorist attacks to provide ethical cover for its interrogation programme and to remove the ethical barriers for psychologists taking part in such interrogation ${ }^{7}$. What has been described as "one of the greatest ethical breaches in the history of psychology" highlights some of the broader consequences of Donald Trump's view on the adoption of waterboarding and other coercive interrogation techniques: it entails the breakdown of key social institutions 9 .

Article 5 of the Universal Declaration of Human Rights specifies that "no one shall be subjected to torture or to cruel, inhuman or degrading treatment or punishment". The prohibition of torture and other illtreatment is enshrined in international law, including the United Nations Convention against Torture (UNCAT) and the International Covenant on Civil and Political Rights (ICCPR). Yet, Amnesty International reports that in 2015-2016 122 or more countries, including more than half of the signatories of UNCAT, tortured or otherwise ill-treated people (http:// go.nature.com/2kEFtnX).

From Saddam Hussein's prisons to Guantanamo, the new millennium has seen autocracies and democracies engage in torture. While the arguments against torture are primarily ethical and legal, they are pragmatic, too. Torture, as a method for information extraction, just does not work.

References

1. Bonaparte, N. in Correspondance de Napoléon Vol. V (ed. Plon, H.) No. 3605, 128 (Imprimeur de l'Empereur, 1861).

2. O'Mara, S. Why Torture Doesn't Work: The Neuroscience of Interrogation (Harvard Univ. Press, 2015).

3. Goodman-Delahunty, J., Martschuk, N \&. Dhami, M. K. Appl. Cognitive Psych. 28, 883-897 (2014).

4. Russano, M. B., Narchet, F. M., Kleinman, S. M. \& Meissner, C. A. Appl. Cognitive Psych. 28, 847-859 (2014).

5. Holmberg, U. \& Christianson, S.-A. Behav. Sci. Law 20, 31-45 (2002).

6. Committee Study of the Central Intelligence Agency's Detention and Interrogation Program (Senate Select Committee on Intelligence, 2012).

7. Hoffman, D. H. et al. Report to the Special Committee of the Board of Directors of the American Psychological Association: Independent Review Relating to APA Ethics Guidelines, National Security Interrogations, and Torture (APA, 2015); http://go.nature.com/2m12Qbm

8. Elkins, D. N. J. Humanist. Psychol. 56, 99-109 (2015).

9. Arrigo, J. M. Sci. Eng. Ethics 10, 543-572 (2004). 